\title{
TOPLINSKA STABILNOST I PLINOVITI PRODUKTI RAZGRADNJE GOVEĐE KOŽE ZA IZRADU VATROGASNE ČIZME
}

\author{
Sandra Flinčec Grgac ${ }^{1}$, Franka Žuvela Bošnjak', Boris Valečić1, Jadranka Akalović1 \\ ${ }^{1}$ Sveučilište u Zagrebu Tekstilno-tehnološki fakultet, Prilaz baruna Filipovića 28a, 10000 Zagreb, \\ Hrvatska \\ Viner d. o. o., Rusanova 1, 33000 Virovitica, Hrvatska
}

E-mail: sflincec@ttf.hr, franka.zuvela.bosnjak@ttf.hr, bvalecic@gmail.com

Izvorni znanstveni rad

UDK: [685.345:675.031.1]:665.7.035.5

\section{Sažetak}

U radu su ispitana svojstva otpornosti na zapaljenje i širenje plamena dvaju uzoraka vatrootpornih goveđih koža te njihova otpornost na djelovanje topline uz praćenje plinovitih produkata koji se javljaju prilikom toplinske razgradnje. Uzorci su podvrgnuti termogravimetrijskoj analizi (TGA) uz praćenje plinovitih produkata razgradnje (TG-IR) tijekom dekompozicije. S obzirom na rezultate gorivosti zaključeno je da ispitivani uzorci glatke goveđe kože pokazuju zadovoljavajuću stabilnost na djelovanje plamena i topline, dok je perforirana brušena vatrootporna koža s umjetnim licem djelomično pougljenila i skupila se u području neposrednog dodira s plamenom. Oba uzorka pokazuju slično ponašanje tijekom TGA, no razlike su uočene prilikom analize plinovitih produkata razgradnje.

\section{Ključne riječi}

goveđa koža, vatrogasna čizma, TG-IR analiza, otpornost na gorenje

\section{UVOD}

Vatrogasno zanimanje jedno je od zanimanja gdje se čovjek svakodnevno nalazi u iznimno opasnim situacijama, stoga vatrogasna oprema ima važnu ulogu u osobnoj zaštiti vatrogasaca. Čizme su, kao dio opreme, iznimno važne za zaštitu nogu od plamena i visokih temperatura, kao i za zaštitu od opasnih tekućina (kemikalija), od mehaničkog i električnog djelovanja [1].

S obzirom na različitu namjenu i vrstu poslova koje vatrogasci obavljaju, postoji nekoliko tipova vatrogasne obuće. Vatrogasna obuća napravljena za sigurnu zaštitu od opasnosti u borbi protiv požara posjeduje svojstva otpornosti na toplinska i mehanička oštećenja. Istodobno, odlikuje se dobrim antistatičkim svojstvima te posjeduje vrlo visok stupanj izolacije na visoke i niske temperature [1].

Vlaknata struktura kožnog tkiva izgrađenog od spleta kolagenih vlakana daje gotovoj koži određena mehanička svojstva koja ovise o vrsti i kvaliteti sirovine te o tehnološkim operacijama obrade. Goveđa koža ima općenito čvrsto i zbijeno kolageno tkivo, naročito u leđnim dijelovima pa se upotrebljava za izradu gotovih koža od kojih se zahtijeva velika otpornost na mehanička naprezanja [2].

Za izradu dijelova cipela koji su izloženi najvećim mehaničkim i toplinskim utjecajima najčešće se upotrebljava leđni (kruponski) dio. Leđni se dio sastoji od gustoga i pravilno isprepletenoga kožnog tkiva, ravnomjerne debljine, zbog čega se odlikuje dobrim mehaničkim svojstvima. Što je više okomitih vlakana, kožno je tkivo čvršće i gušće. Leđni dio kože dio je kožnog tkiva koji je najčvršći i najgušći što osigurava dobra mehanička i toplinska svojstva [3].
Vatrogasne čizme najčešće se izrađuju od goveđeg boksa. Boks kože, kromno ili kombinirano uštavljene, upotrebljavaju se za izradu gornjih dijelova obuće i u galanterijske svrhe. Uglavnom se obrađuju s glatkim prirodnim licem te lomljenim ili utisnutim licem. Glavna svojstva boks koža jesu: punoća, gipkost, mekoća, dobra čvrstoća, elastičnost i gusta građa kožnog tkiva. Navedena se svojstva povezuju s vlaknatom strukturom kožnog tkiva izgrađenog od spleta kolagenih vlakana, a ovise o vrsti i kvaliteti sirovine te o provedenim tehnološkim operacijama obrade [2].

Praćenje toplinske razgradnje kože dosad je upotrebljavano za identifikaciju povijesnih i kulturnih predmeta izrađenih od kože, definiranje razlika između prirodnih i umjetnih koža, u restauraciji povijesnih predmeta te za procjenu rizičnih utjecaja u primjeni i na okoliš [4].

Vatrogasna obuća klasificira se i ispituje prema normi HRN EN ISO 15090:2012.

SPECIAL FIGHTER CE 0197 EN 15090:2012 HI3 CI SRC - Tip F2A

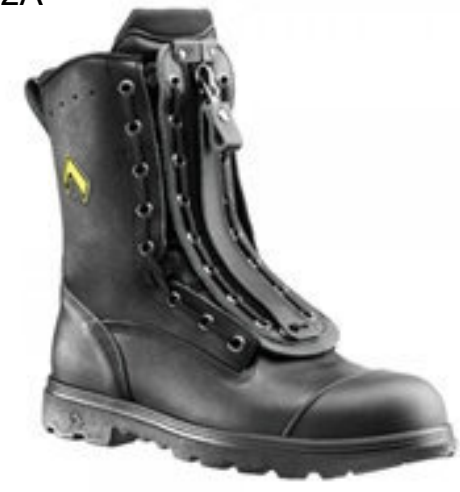

Slika 1. Vatrogasna čizma, Special Fighter 
Gornjište je izrađeno od prvoklasne goveđe kože debljine do $3 \mathrm{~mm}$, čvrste i vrlo stabilne strukture, izvrsne prozračnosti te homogene i neoštećene površine kože koja ne sadržava štetne tvari. Udio kože u ovoj je vatrogasnoj čizmi 70 \%. Upotrebljavaju se samo kože vrhunske kvalitete koje moraju biti prozračne, hidrofobirane, bez štetnih tvari $\left(\mathrm{PCP}^{1} \mathrm{i}\right.$ Krom VI itd.), s dodatkom pigmenata koji reflektiraju sunčevu svjetlost.

Za podstavu se upotrebljava materijal Cambrelle ${ }^{\circledR}$ tvrtke GORE-TEX®, četveroslojni laminat $s$ membranom od PTFE $^{2}$ koji podnosi temperature do $260^{\circ} \mathrm{C}$, prozračan je i vodonepropusan [5]. Testiran je na 500000 „trljanja“ tkanine što je dvostruko više od propisanog standarda. Čizma s ovakvom podstavom pruža višestruku zaštitu i održava povoljne mikroklimatske uvjete. Čizma ima gumeni potplat, „samočisteći“, V-profila koji osigurava bolji oslonac i vučnu snagu na neravnom terenu. Takav potplat relativno je male težine, ne ostavlja tragove, otporan je na ulje i goriva. $U$ potplat je ugrađena metalna tabanica za zaštitu od oštrih objekata. MLS sustav ravnomjerno raspoređuje težinu tijela na potplat, ublažava opterećenje kralježnice, apsorbira i distribuira energiju pri pokretima, izolira gornjište od topline i hladnoće te permanentno povezuje gornju kožu, uložak i potplat.

$\mathrm{Na}$ prednjem dijelu gornjišta, osim čelične kapice, ugrađena je i TPU kapica. Ona služi za zaštitu od abrazije i raznih vanjskih utjecaja kao ulje i goriva te produljuje vijek trajanja čizme [5].

Prema normi HRN EN ISO 15090:2012, vatrogasna se obuća testira na utjecaj temperature prema sljedećim točkama:

1. Kontakt potplata $s$ vrelom površinom: pijesak temperature $250^{\circ} \mathrm{C} \mathrm{u}$ vremenu od 40 minuta. Nakon testa materijal ne smije biti vidljivo oštećen, a stupanj izolacije mora biti zadovoljavajući.

2. Isijavanje: cijela je čizma izložena toplini $2 \mathrm{~W} / \mathrm{cm}^{2}$ (približno $300^{\circ} \mathrm{C}$ ) u vremenu od 3 minute. Materijal ne smije biti vidljivo oštećen

3. U plamenu usmjerenom na gornjište: svi gornji materijali testirani su na otvoreni plamen u vremenu od 15 sekundi. Nakon odmicanja s plamena materijali ne smiju gorjeti više od 2 sekunde i ne smiju isijavati pohranjenu toplinu više od 5 sekundi [6].

PCP - pentachlorophenol, upotrebljava se kao sredstvo za sprečavanje rasta gljivica u kožarskoj industriji

${ }^{2}$ PTFE - politetrafluoretilen, poznatiji kao „teflon“

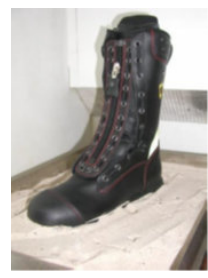

a

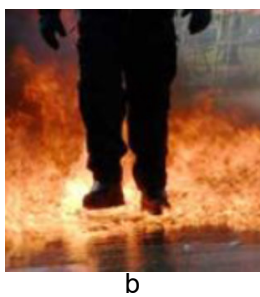

b

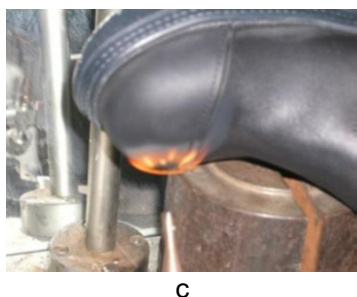

C
Slika 2. Testiranje čizme prema HRN EN ISO 15090:2012: a) potplat $S$ vrelom površinom, b) isijavanje, c) plamen usmjeren na gornjište.
Tablica 1. Klasifikacija vatrogasne obuće prema HRN EN ISO 15090:2012

\begin{tabular}{|c|l|}
\hline Kôd 1 & $\begin{array}{l}\text { obuća od kože ili drugih materijala, s izuzetkom pune } \\
\text { gume ili obuće od polimera }\end{array}$ \\
\hline Kôd 2 & obuća od pune gume ili cipele potpuno od polimera \\
\hline
\end{tabular}

Tablica 2. Tipovi obuće za vatrogasce prema normi HRN EN ISO 15090:2012

\begin{tabular}{|c|l|}
\hline Tip 1 & $\begin{array}{l}\text { pogodne za opću tehničku ispomoć (npr. Tip 1, HI1) i za } \\
\text { borbu protiv požara samo na otvorenom (npr. Tip 1 HI2, } \\
\text { Tip 1 HI3) }\end{array}$ \\
\hline Tip 2 & $\begin{array}{l}\text { teške, modelirane za osnovnu zaštitu, pogodne za } \\
\text { intervenciju unutra i druge požare svih vrsta; standardne } \\
\text { vatrogasne čizme (npr. Tip 2 HI2; Tip 2 HI3) }\end{array}$ \\
\hline Tip 3 & $\begin{array}{l}\text { verzija specijalne zaštite, pogodne za uporabu pri } \\
\text { posebnim rizicima kao, primjerice, intervencija na } \\
\text { opasnim materijalima; također pogodne za sve vrste } \\
\text { borbe protiv požara (npr. Tip 3 HI2, Tip 3 HI3) }\end{array}$ \\
\hline Značenje kratica simbola \\
\hline HI1 & $\begin{array}{l}\text { razina učinka izolacije od topline u području potplata pri } \\
150^{\circ} \mathrm{C} / 30 \text { min. }\end{array}$ \\
\hline HI3 & $\begin{array}{l}\text { razina učinka izolacije od topline u području potplata pri } \\
250^{\circ} \mathrm{C} / 40 \text { min. }\end{array}$ \\
\hline
\end{tabular}

Međunarodna norma HRN EN ISO 20345:2012 određuje osnovne i dodatne uvjete za sigurnosnu obuću. To uključuje mehanički i toplinski rizik, otpornost na proklizavanje, ergonomsko ponašanje. Sustav klasifikacije koji se upotrebljava za određivanje zaštite koju obuća nudi prikazan je u tablici 3 [7].

Tablica 3. Sustav klasifikacije za određivanje zaštite

\begin{tabular}{|c|l|}
\hline $\begin{array}{c}\text { Oznaka } \\
\text { klasifikacije }\end{array}$ & \multicolumn{1}{|c|}{ Opis klasifikacije } \\
\hline SB & $\begin{array}{l}\text { Postojanje sigurnosne kapice za prste koja pruža } \\
\text { zaštitu prstiju od ozljeda prilikom pada predmeta. } \\
\text { Razina zaštite je 200 J. Prevencija ozljede nastale } \\
\text { uslijed pritiska na prste koji su pritisnuti teškim } \\
\text { predmetom. Razina ove zaštite je 15 kN. }\end{array}$ \\
\hline SBP & $\begin{array}{l}\text { kao SB standard + otpornost na prodiranje } \\
\text { kao SB standard + zatvorena peta te antistatička } \\
\text { svojstva, otpornost na upijanje goriva, ulja i energije } \\
\text { tog dijela }\end{array}$ \\
\hline S1 & kao S1 standard + otpornost na prodiranje \\
\hline S1P & $\begin{array}{l}\text { kao S1 standard + otpornost na prodiranje i } \\
\text { apsorpciju vode }\end{array}$ \\
\hline S2 + rebrasti potplat i otpornost na \\
\hline S3 & $\begin{array}{l}\text { kao S4 standard + rebrianje } \\
\text { prodiran prate koja pruža zaštitu od 200 J. Sva }\end{array}$ \\
\hline S4 & $\begin{array}{l}\text { Kapica za prste } \\
\text { gumena ili obuća izrađena od polimera s } \\
\text { antistatičkim svojstvima. Otpornost na loživo ulje, } \\
\text { apsorpciju energije na peti te zatvoren isti dio. }\end{array}$ \\
\hline S5 & $\begin{array}{l}\text { kao S4 standard + rebrasti potplat i otpornost na } \\
\text { prodiranje }\end{array}$ \\
\hline HI & izolacija topline \\
\hline Cl & izolacija hladnoće \\
\hline WRU & nepromočivo gornjište \\
\hline WR & vodonepropusnost \\
\hline I & električno izolirana cipela \\
\hline SRC & protuklizni potplat \\
\hline HRO & otpornost na kontakt s toplinom \\
\hline M & zaštita metatarzalne kosti \\
\hline AN & zaštita gležnja \\
\hline FO & otpornost potplata na goriva \\
\hline
\end{tabular}

\section{EKSPERIMENTALNI DIO}

\subsection{Opis uzoraka}

Ispitivanju toplinske stabilnosti i vatrootpornosti podvrgnuta su dva uzorka goveđe kože. Vatrootporni goveđi boks (VK1), debljine 2,3-2,5 mm, upotrebljava se za izradu lica vatrogasne čizme. Perforirana brušena goveđa koža (VK2) s nanosom umjetnog lica, najčešće se upotrebljava za kragnu vatrogasne čizme. Oba su uzorka crne boje. 


\subsection{Postupak ispitivanja toplinske stabilnosti}

Termogravimetrijska analiza (TGA) uzoraka kože izvedena je pomoću analizatora PerkinElmer kojim je upravljao PC sustav, u atmosferi s protokom sintetičkog zraka (30 \% kisika; brzina protoka $60 \mathrm{ml} / \mathrm{min}$ ). Termogravimetri (TG) uzoraka dobiveni su u temperaturnom rasponu od $50{ }^{\circ} \mathrm{C}$ do $850{ }^{\circ} \mathrm{C}$ pri brzini grijanja od $30{ }^{\circ} \mathrm{C} / \mathrm{min}$. Prije termičke analize, uzorci koža izrezani su na komadiće prosječne težine $1 \mathrm{mg}$, a analizirani uzorci težili su približno $6 \mathrm{mg}$. Uzorci su proučavani i kombiniranom termogravimetrijskom analizom uz praćenje plinovitih produkata razgradnje na infracrvenom spektrometru (TG-IR tehnikom) kako bi se dobio uvid u sastav plinovitih produkata razgradnje. Za TG-IR analizu upotrijebljena je termička stanica za analizu plinova (EGA) opremljena detektorom. Prijenosni vod, stanica prijenosa visoke temperature i TG sučelje držani su pod $280{ }^{\circ} \mathrm{C}$ tijekom izvođenja mjerenja kako bi se spriječila kondenzacija plina. Peristaltička pumpa prenijela je nastale plinove uz brzinu protoka od $60 \mathrm{ml} / \mathrm{min}$.

\subsection{Postupak ispitivanja svojstva otpornosti na gorenje}

Ispitivanje provedeno u skladu $s$ HRN EN ISO 15025:2016 i HRN EN ISO 15090:2012, t, 7.3. [8, 9]. Uzorci su prije ispitivanja stavljeni u uvjete standardne atmosfere temperature $23^{\circ} \mathrm{C} \quad\left( \pm 2{ }^{\circ} \mathrm{C}\right)$ i relativne vlažnosti $50 \%$ ( $\pm 5 \%)$.

\section{REZULTATI I RASPRAVA}

Rezultati ispitivanja toplinske stabilnosti i plinovitih produkata tijekom termičke razgradnje prikazani su na slikama 3, 4, 5 i 6.

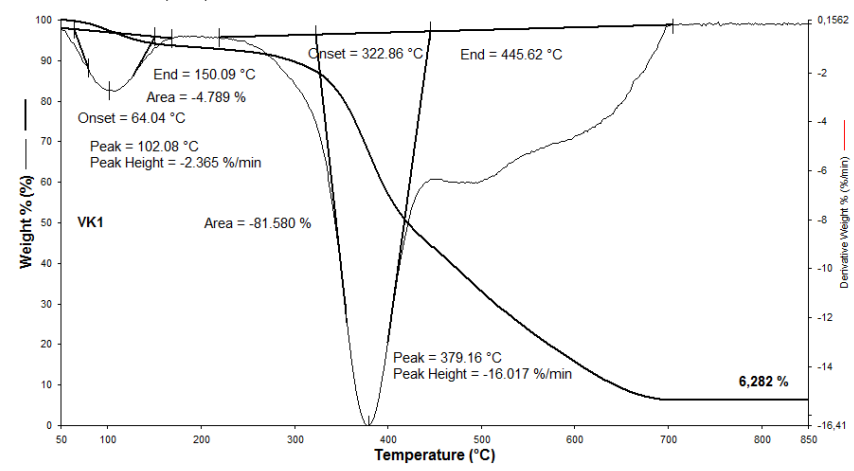

Slika 3. TG krivulje i prva derivacija TG krivulje (dTG) uzorka goveđe kože za izradu vatrogasne čizme (VK1)

Iz dobivenih termogravimetrijskih krivulja (TG) i njezinih prvih derivacija (DTG) jasno je vidljivo da se razgradnja uzoraka VK1 i VK2 (slika 3 i slika 5) odvija u dva razgradbena stupnja. Pri temperaturi od $102,08{ }^{\circ} \mathrm{C}$ kod VK1 i $92,78{ }^{\circ} \mathrm{C}$ kod VK2 zabilježeni su prvi stupnjevi dinamičke razgradnje u kojima je došlo do otpuštanja nevezane i kristalno vezane vode što je vidljivo iz slike $4 \mathrm{~b}$ i slike 6 b po detektiranim plinovitim produktima vode i $\mathrm{H}_{2}$. $\mathrm{U}$ drugom stupnju dinamičke razgradnje uzorka VK1 na temperaturi od $379,16{ }^{\circ} \mathrm{C}$ zabilježen je gubitak mase od 16,017 \% u minuti (slika 3) te pri temperaturi $367,65^{\circ} \mathrm{C}$ kod uzorka VK2 gubitak mase je iznosio $16.148 \%$ u minuti (slika 5). Navedena dinamika razgradnje kod oba uzorka upućuje na dekompoziciju strukture kožnog tkiva koja je uzrokovana isušivanjem kože i taljenjem kristalinične strukture kolagena uz pojavu sljedećih plinovitih produkata (slika $4 \mathrm{c} \mathrm{i} \mathrm{d,} \mathrm{slika}$ $6 \mathrm{c} \mathrm{i} \mathrm{d):} \mathrm{kristalno} \mathrm{vezane} \mathrm{vode} \mathrm{pri} \mathrm{valnom} \mathrm{broju} 3500$ $4000 \mathrm{~cm}^{-1}, \mathrm{CO}_{2}$ potvrđuje pik koji se nalazi između valnih brojeva $2402-2240 \mathrm{~cm}^{-1}$ i $736-605 \mathrm{~cm}^{-1}$, a može nastati prilikom razgradnje kožnog tkiva izravnim dekarboksiniranjem - $\mathrm{COOH}$ i uslijed kondenzacijskih reakcija koje uključuju peptidne -CO- skupine te uslijed interne oksidacije drugih organskih skupina u kožnom tkivu, $\mathrm{CO}$ u području $2240-2060 \mathrm{~cm}^{-1}, \mathrm{NH}_{3}$ identificiran je u oba uzorka (VK1 i VK2) gdje je uočena pojava uskih pikova pri valnom području od 1200 do $750 \mathrm{~cm}^{-1}$ s karakterističnim vrpcama na $964,930 \mathrm{~cm}^{-1} . \mathrm{CH}_{4}$ i C $\mathrm{H}_{6}$ plinoviti produkti razgradnje vidljivi su u području 2800 do $3000 \mathrm{~cm}^{-1}$ kod uzorka VK2 (slika 6 d). Kod istog uzorka na valnom broju $2080 \mathrm{~cm}^{-1}$ uslijed raspada kolagena zabilježeni su produkti HNCO, a pri valnom broju $1710 \mathrm{~cm}^{-1}$ zabilježena je pojava plinovitog produkta aldehida $\mathrm{C}=\mathrm{O}[4,10]$. Zbog pojave veće količine različitih plinovitih produkata prilikom toplinske dekompozicije uzorak VK2 upućuje na mogući štetni utjecaj na zdravlje i okolišs.
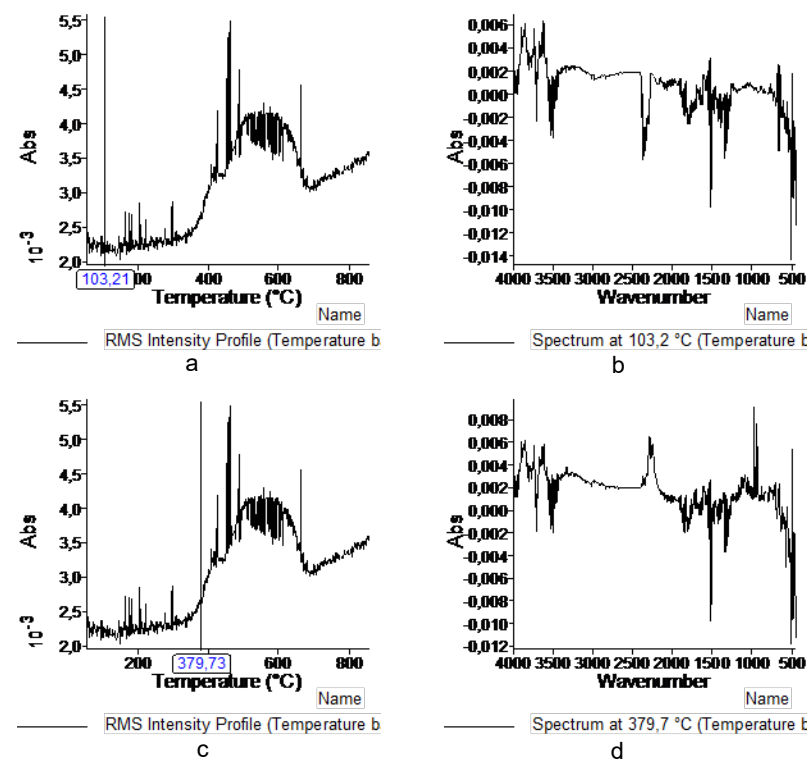

Slika 4. TG-IR analiza uzorka goveđe kože VK1: a) apsorpcijski spektar veće koncentracije plinova, b) izmjereni plinovi na IR-u pri temperaturi $103,2{ }^{\circ} \mathrm{C}$, c) drugi apsorpcijski spektar, d) izmjereni plinovi na IR-u pri temperaturi $379,73{ }^{\circ} \mathrm{C}$

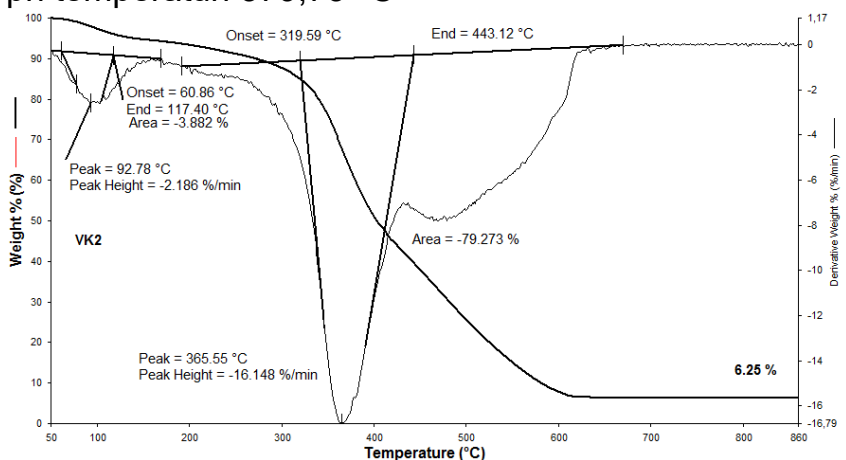

Slika 5. TG krivulje i prva derivacija TG krivulje (dTG) uzorka goveđe kože s perforacijama i doradom lica za izradu vatrogasne čizme (VK2) 

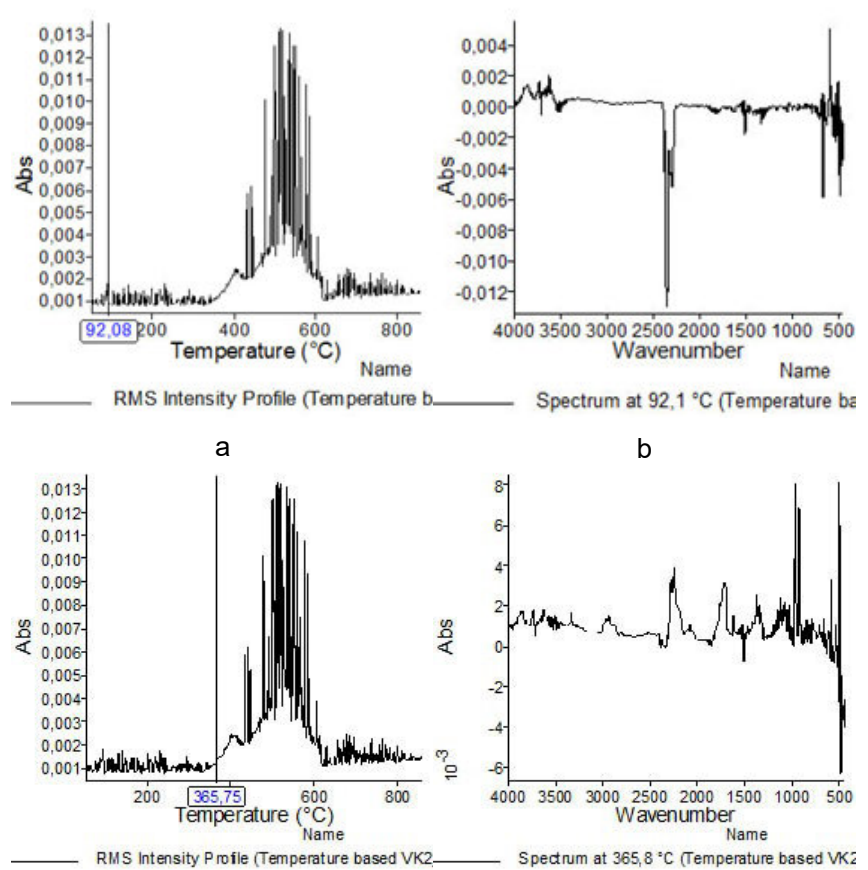

$\mathrm{C}$

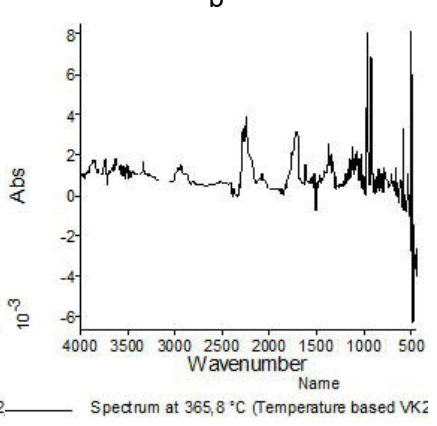

d

Slika 6. TG-IR analiza uzorka goveđe kože VK2: a) apsorpcijski spektar veće koncentracije plinova, b) izmjereni plinovi na IR-u pri temperaturi $92,21^{\circ} \mathrm{C}, \mathrm{c}$ ) drugi apsorpcijski spektar, d) izmjereni plinovi na IR-u pri temperaturi $365,75^{\circ} \mathrm{C}$

\subsection{Rezultati ispitivanja otpornosti na gorenje}

Nakon gašenja plamena nijedan uzorak nije nastavio gorjeti. Gotova vatrootporna koža goveđeg boksa VK1 nije bila oštećena i idealni je materijal za izradu lica vatrogasne čizme, međutim, VK2, perforirana brušena goveđa vatrootporna koža s umjetnim licem djelomično je pougljenila i skupila se u sredini (slika 7), gdje je bila naslonjena na plamen. Zbog spomenutih oštećenja i deformacija uzorak VK2 pokazao se kao neodgovarajući materijal za izradu dijela vatrogasne čizme.

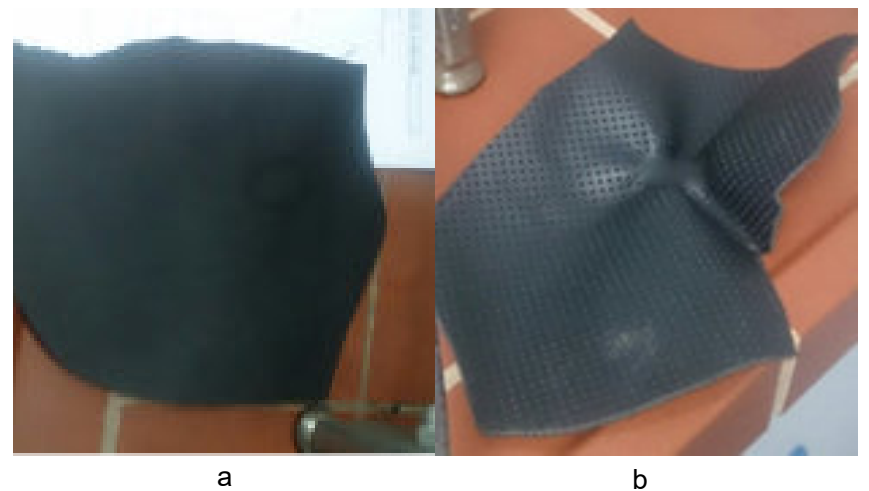

Slika 7. Uzorci nakon provedenog ispitivanja otpornosti na gorenje: a) VK1, b) VK2

\section{ZAKLJUČAK}

Termogravimetrijske analize uzoraka goveđe kože upućuju na njihovu približno jednaku toplinsku stabilnost. Detaljnijom analizom termogravimetrijskih krivulja jasno je vidljivo da uzorak VK1 ima veću toplinsku stabilnost jer je konačni ostatak formiran na temperaturi od $700{ }^{\circ} \mathrm{C}$, dok je kod uzorka VK2 taj ostatak formiran na temperaturi od $600{ }^{\circ} \mathrm{C}$. Plinoviti produkti razgradnje jasno upućuju na prisutnost različitih plinova. Kod uzorka perforirane goveđe kože vidljiva je pojava plinovitog izocianata koja može uputiti na primjenu poliuretanske dogotove lica perforirane goveđe kože VK2. Oba uzorka prilikom toplinske razgradnje proizvode plinoviti $\mathrm{NH}_{3}$ koji je toksičan i korozivan, no analizom snimljenih plinovitih spektara $u$ cijelom rasponu toplinske razgradnje vidljivo je da pri temperaturama višima od $500{ }^{\circ} \mathrm{C}$ nije zabilježena njegova pojava. Veći broj potencijalno štetnih plinova zabilježen je kod uzorka VK2 i može se povezati s vrstom i strukturom dovršnih opni na licu kože. Uzorak VK1 pokazuje veću stabilnost na djelovanje otvorenog plamena i otpušta manje plinovitih produkata tijekom toplinske razgradnje te je kao takav mnogo povoljniji za izradu vatrogasnih čizama. $U$ daljnjim istraživanjima nastojat će se proučiti utjecaj različitih ekološki povoljnijih sredstava za smanjenje gorivosti goveđe kože radi smanjenja plinovitih produkata štetnih za okoliš.

\section{ZAHVALA}

Rad je financiran sredstvima dobivenima u sklopu potpore istraživanjima TP8/17, Funkcionalizacija i karakterizacija tekstilnih materijala za postizanje zaštitnih svojstava, voditeljice dr. sc. Sandre Flinčec Grgac, doc.

Rad je objavljen na VII. međunarodnom stručnoznanstvenom skupu Zaštita na radu i zaštita zdravlja, Zadar, Hrvatska.

\section{LITERATURA}

[1] Park, H. i sur. 2015. Effect of firefighters' personal protective equipment on gait. Applied Ergonomics, Vol. 48, pp. $42-48$, ISSN 0003-6870.

[2] Grgurić, H. i sur. 1985. Tehnologija kože i krzna. Zajednica kem., kožarskih, obućarskih, gum. i rud. organizacija. Zagreb.

[3] Radanović, Z. 1989. Poznavanje kožarskih materijala i njihovo ispitivanje. Zagreb.

[4] Marcillaa, A. i sur. 2011. Study of the influence of $\mathrm{NaOH}$ treatment on the pyrolysis of different leather tanned using thermogravimetric analysis and Py/GC-MS system. Journal of Analytical and Applied Pyrolysis, Vol. 92, pp. 194 - 201, ISSN: 0165-2370.

[5] http://hzzzsr.hr/wp_content/uploads/2016/11/Osobna_zasti tna_oprema_za_zastitu_nogu_i_stopala.pdf, pristupljeno: 20. 1. 2019.

[6] www.financ-fire.com/Norme.pdf, pristupljeno 20. 1. 2019.

[7] www.financ-fire.com/Proizvodnja.pdf, pristupljeno 20. 1. 2019.

[8] HRN EN ISO 15025:2016. Zaštitna odjeća - Zaštita od plamena - Metoda ispitivanja ograničenog širenje plamena

[9] HRN EN ISO 15090:2012, t,7.3 - Obuća za vatrogasce Ispitivanje otpornosti na gorenje

[10] Bańón, E. i sur. 2016. Kinetic model of the thermal pyrolysis of chrome tanned leather treated with $\mathrm{NaOH}$ under different conditions using thermogravimetric analysis. Waste Management, Vol. 48, pp. 285 - 299, ISSN: 0956-053X. 